\title{
Pozzolanic effect investigation of silica hydrosol (SH) nanoparticles with different granulometric distributions dispersed in cement paste
}

\author{
Diogo Augusto da Silva de Assis ${ }^{1}$, \\ Mariana d’Orey Gaivão Portella Bragança ${ }^{2}$
}

\footnotetext{
${ }^{1}$ Lactec/IEP, Next Chemical - Rua João Chede, $n^{\circ}$ 2245, Cidade Industrial, CIC, Curitiba - PR, Brazil,

${ }^{2}$ Lactec/IEP - Rod. BR-116, km 98, nº 8.813 - Prédio LAME - Jardim das Américas, Curitiba, PR, Brazil. e-mail: diogoasassis@gmail.com, mariana.portella@lactec.com.br
}

\begin{abstract}
The addition of nanomaterials to concrete allows structural modifications, improving their properties like mechanical strength and durability. Within these possible nanoscale materials is silica hydrosol (SH). There are many studies highlighting the influence of the surface area of SH particles on the pozzolanic reaction with cement, however little has been studied on the influence of percentage and particle size on the reaction. In this context, the objective of this work was to investigate the influence of the particle size distribution of silica nanoparticles on the pozzolanic reaction in cement pastes, from the comparison of 4 colloidal suspensions. The addition content of these particles, with different sizes, was defined as $3.00 \%$ (SH-A), $0.89 \%$ (SH-B), $0.77 \%$ (SH-C) and $0.32 \%$ (SH-D), to equalize the surface areas of all of them, so that the only variables were the percentage and particle size distribution of the silicas. The pozzolanic effect was evaluated by the direct method named Modified Chapelle test, and by indirect methods like Fourier transform infrared spectroscopy (FT IR), and mechanical strength tests. It was concluded that for the same surface area resulting from the addition of $\mathrm{SH}$, the sample that presented the best performance was the $\mathrm{CP} \mathrm{SH}-\mathrm{A}$, which presented the largest particle size and volume of addition. However, when analysing the relative performance, regarding the concentration of SH added to the paste, the $\mathrm{CP}$ SH-D sample obtained the highest mechanical resistance and the highest pozzolanic index. It showed that concentration and particle size, not just surface area, influenced the performance of the nanosilica pozzolanic reaction. The conclusions obtained in the present work allow a better understanding about the addition of $\mathrm{SH}$ in cementitious composites and how the content and particle size of such products impact their performance.
\end{abstract}

Keywords: Nanoaddition, Silica Hydrosol, Cement Paste, Pozzolanic Effect

\section{INTRODUCTION}

The demand for stronger and more durable structures capable of withstanding higher compressive and flexural forces has stimulated the development of research in the area of cementitious compounds and nanotechnology. The addition of nanomaterials to the cement mix allows structural modifications of the concrete, improving its properties, like mechanical strength and durability [1-2]. Within these possible nanoscale materials, there is colloidal silica (SC), which can be in water solution, called SH [3].

In recent years, much attention has been focused on $\mathrm{SH}$ applications in cementitious composites for property improvement. As $\mathrm{SH}$ is an aqueous suspension, it is more easily dispersed during the concrete dosage, and its potential for addition is increased [4].

The addition of SH due to its surface area $\left(50-900 \mathrm{~m}^{2} / \mathrm{g}\right)$, degree of crystallinity and purity is highly reactive. Thus, this material has the potential to bind to the remaining portlandite or calcium hydroxide, forming additional calcium silicate hydrate $(\mathrm{C}-\mathrm{S}-\mathrm{H})$ and consequently promoting mechanical strength gain, decreased porosity and increased durability [5]. In addition, due to its area and surface reactivity, acts as nucleation site of cement hydration products, promoting acceleration in the dissolution and hydration process and consequently, the gain of mechanical strength [6-7].

According to KUNTHER et al. [8], another form of SH performe in the cementitious medium is decreasing the $\mathrm{Ca} / \mathrm{Si}$ ratio. This happens because the addition of SH in cement paste, increase the Si value in the medium, decreasing the difference between $\mathrm{Ca}$ and $\mathrm{Si}$ quantity. This results in the elongation and 
densification of the silicate chains that form the $\mathrm{C}-\mathrm{S}-\mathrm{H}$ gel. The authors concluded that the compressive strengths of the $\mathrm{C}-\mathrm{S}-\mathrm{H}$ pastes increases with decreasing $\mathrm{Ca} / \mathrm{Si}$ ratio.

The addition, due to its small size, still acts as a filler, that is, it occupies the empty physical spaces of the cementitious composite, reducing porosity and densifying the mixture. The inclusion of SH also enables modification of the cementitious composite in both fresh and hardened state, even when compared with other mineral additions [9]. It is happened because this material has the ability to decrease the setting time and accelerate the hydration of cementitious composites compared to the addition of microsilica.

The inclusion of $\mathrm{SH}$ allows the reduction of cement paste porosity and increase of silicate chains, enhancing the mechanical strength and durability of the composite [10]. There are studies showing several benefits resulting from the use of $\mathrm{SH}$ in cementitious composites: GAITERO et al. [11] verified the influence of the addition of 3 types of SH with different particle sizes and 1 type of NSP in the cement paste. The authors concluded that the compressive strength for the SH sample with a size of $20 \mathrm{~nm}$ was the most reactive, presenting higher compressive strength (20 to 30\% higher than the reference) and higher pozzolanic activity, as measured by X-ray Diffraction (XRD). They explained the increase in mechanical strength due to the pozzolanic reaction promoted by the addition of $\mathrm{SH}$, which reduced the porosity of the cement composite. BERRA et al. [12] investigated the effect of the addition of SH on the workability and compressive strength of cement pastes using a mass content of $0,0.8$ and 3.8 mass $\%$ of cement. They concluded that the addition of SH resulted in a mechanical strength gain of around 7 to $12 \%$ over the reference sample for 7 days of cure.

More recently, RUPASINGHE et al. [13] used SH as an addition to replace part of the cement content in cement pastes. The compound was added to replace cement at 4,8 and $12 \%$ by mass, with a w/c (water/cement) ratio of 0.3 . The replacement of SH (12\%) has been shown to reduce the amount of calcium hydroxide in the medium by $40-50 \%$ compared to the standard sample. In addition, $\mathrm{SH}(8 \%)$ improved the mechanical strength of cement paste by 30 to $40 \%$ for 28 days of cure, which was attributed to the pozzolanic reaction promoted by SH. ZHANG et al. [14] evaluated the influence of adding different particle sizes of SH $(30,60$ and $140 \mathrm{~nm})$ to cement paste. The SH sample with a particle size of $30 \mathrm{~nm}$ had a higher pozzolanic activity among them and the produced sample presented $32 \%$ less calcium hydroxide than the reference one for 3 days. The authors related that to the larger surface area and smaller particle size of the $30 \mathrm{~nm}$ sample.

Despite these examples of efficiency in the use of $\mathrm{SH}$, there are still studies that show contrary results, compared to the major publications in area. DURGUN and ATAHAN [15], for example, evaluated the influence of the addition of SH with fumed silica on self-compacting concrete. Different sizes of SH were used and the properties of compressive strength and pozzolanic activity were evaluated. The authors found that the $5 \mathrm{~nm}$ particle was not the one with the highest pozzolanic yield, but the $17 \mathrm{~nm}$ one. It was contrary to many studies, which state that the smaller the particle the higher its pozzolanic reactivity. Thus, they observed that size and percentage of $\mathrm{SH}$ addition may also be directly related to the efficiency of the pozzolanic reaction, consequently influencing the properties of cementitious mixtures.

Therefore, the objective of this work was to verify the influence of different particle size distributions and SH concentrations on the pozzolanic reaction in cement paste in order to improve the knowledge of the application of this technology in the civil construction sector.

\section{MATERIALS AND METHODS}

\subsection{Materials}

The binder used was the initial high-strength sulphate-resistant Portland Cement (CP-V ARI-RS). According to the manufacturer the product presented characteristics in accordance with the ABNT NBR 16697:2018 [16] specifications. The water used for the cement pastes and modified Chapelle tests agreed with the potability criteria recommended by ABNT NBR 15900-1:2009 [17], which requires the water to be potable.

The additions that have been used are four commercially available aqueous silica suspensions. The samples have different particle size distributions to compare them each other. Table 1 shows the particle sizes and surface areas of each SH used.

For the characterization of the SH samples, the powder method diffraction technique, by XRD, was used. The samples were prepared with oven drying for $24.00 \mathrm{~h}$ at $60.00^{\circ} \mathrm{C}$, in order to avoid possible damage to the structure of SH's. At the end of this process, the samples were milled to fine particle size and passed through a 200 mesh sieve to obtain uniform size particles. The fine powder was prepared in the sample holder and inserted into the measuring equipment. 
Table 1: Specifications of Mineral Additions Used.

\begin{tabular}{c|c|c|c}
\hline \multirow{2}{*}{ SAMPLES } & PARTICLE SIZE & SUPERFICIAL AREA & CONCENTRATION \\
\cline { 2 - 4 } & $\mathrm{nm}$ & $\mathrm{m}^{2} / \mathrm{g}$ & $\%(\mathrm{w} / \mathrm{w})$ \\
\hline SH-A & 35.00 & $80.00 \mathrm{~m}^{2} / \mathrm{g}$ & 50.00 \\
\hline SH-B & 12.00 & $270.00 \mathrm{~m}^{2} / \mathrm{g}$ & 40.00 \\
\hline SH-C & 8.00 & $310.00 \mathrm{~m}^{2} / \mathrm{g}$ & 30.00 \\
\hline SH-D & 3.00 & $750.00 \mathrm{~m}^{2} / \mathrm{g}$ & 15.00 \\
\hline
\end{tabular}

The tests were performed on an X-ray Diffractometer, D2 PHASER, Bruker. The analysis was performed between $5.00^{\circ}$ and $70.00^{\circ} 2 \theta$, with angular step of $0.02^{\circ} 2 \theta$ and time per step of $1.00 \mathrm{~s}$. In the collection, a tube with copper anode, $30 \mathrm{kV} / 10 \mathrm{~mA}$ and divergent slot of 1 was used.

The diffractogram of the evaluated $\mathrm{SH}$, as shown in Figure 1, showed that, for all samples, the silica had no organized or crystalline structure and was therefore amorphous. The amorphous halo, identified in position 21.80-22.00 ${ }^{\circ}$ degree, based EVA software library and literature [18], represents $\mathrm{SiO}_{2}$ from dried CS powder. The area of the amorphous halo of each sample was calculated by EVA software and the results are shown in Table 2. It was possible to identify that the area is similar for the four samples and based on ANOVA and Tukey test the results has no significantly differences. These means that the SH samples are equal when related to $\mathrm{SiO}_{2}$ amorphous quality. In addition, it was possible to identify in the diffractogram that there is absence of salts and crystalline impurities, indicating high purity of the addition.
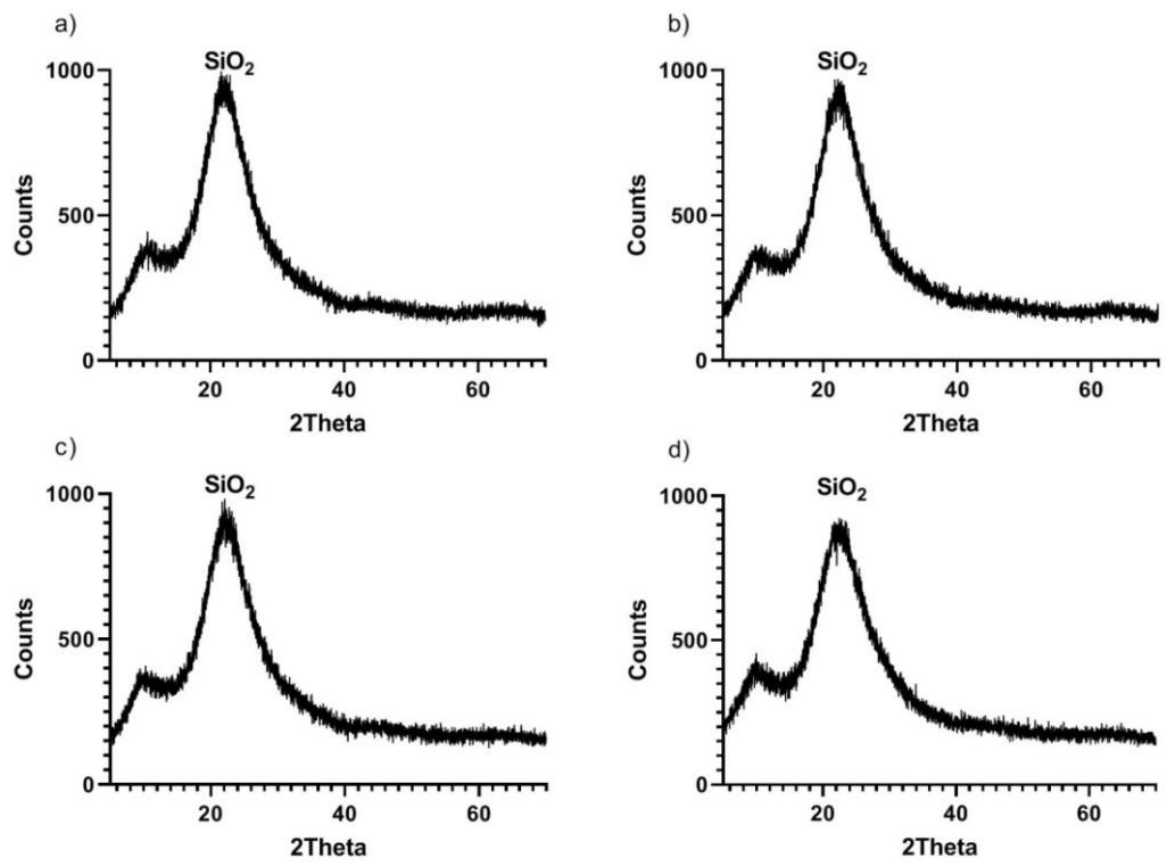

Figure 1: SH samples difratogram. a) SH-A; b) SH-B; c) SH-C; d) SH-D.

For evaluation of the functional groups of the SH samples used in this work, FT IR 70 equipment, equipped with attenuated total reflection accessory (ATR) was used. For the FT IR assays, the SH samples were prepared in similar way to the XRD analysis. For ATR, the samples were placed under direct contact with the diamond crystal. All measurements were collected in the range of $4000-400 \mathrm{~cm}^{-1}$. Spectra were measured at $4.0 \mathrm{~cm}^{-1}$ resolution, accumulating a total of 32 scans per sample analysed. After the measurements, the spectra were organized in sequence for better visualization. Figure 2 shows the FT IR spectra obtained for the SH samples. Based on literature [19-20], it was possible to identify for the wavelength of 430 and $800 \mathrm{~cm}^{-1}$ the appearance of absorption bands, related to the oxygen movements, flexion and bending vibrations in the $\mathrm{Si}-\mathrm{O}-\mathrm{Si}$ plane. In addition, the absorption band at $1000-1150 \mathrm{~cm}^{-1}$ refers to the elongation of the characteristic bands of Si-O bonds. 
Table 2: Amorphous halo area at position $21.80^{\circ}-22.00^{\circ}$ for each $\mathrm{SH}$ sample.

\begin{tabular}{c|c}
\hline \multirow{2}{*}{ SAMPLES } & MEDIUM AREA \\
\cline { 2 - 2 } & counts $\times$ 2theta \\
\hline SH-A & 306.20 \\
\hline SH-B & 305.00 \\
\hline SH-C & 305.20 \\
\hline SH-D & 306.90 \\
\hline
\end{tabular}

a)

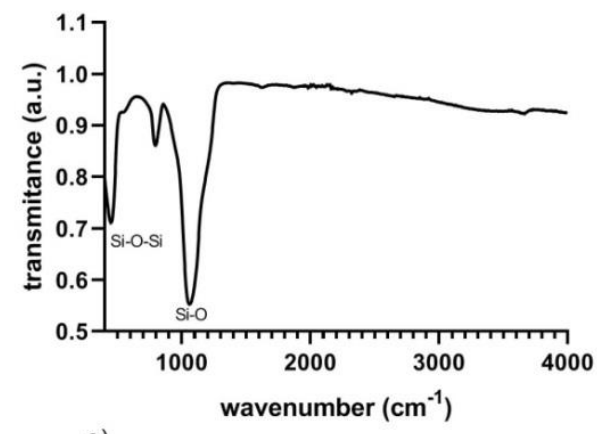

c)

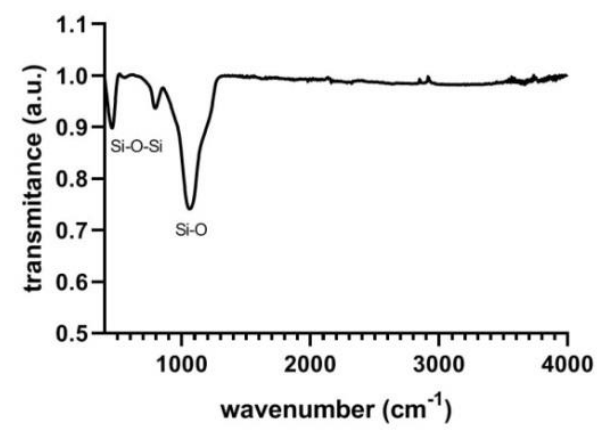

b)

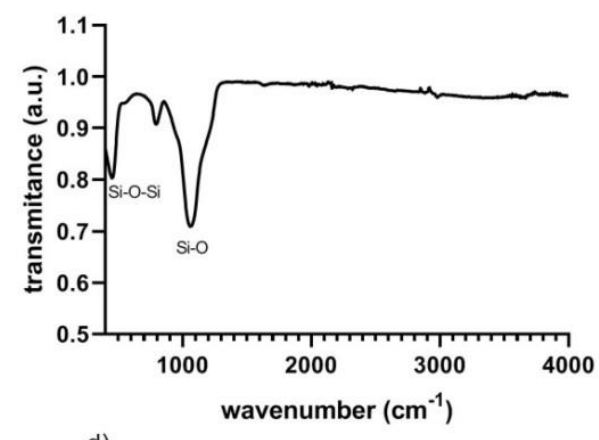

d)

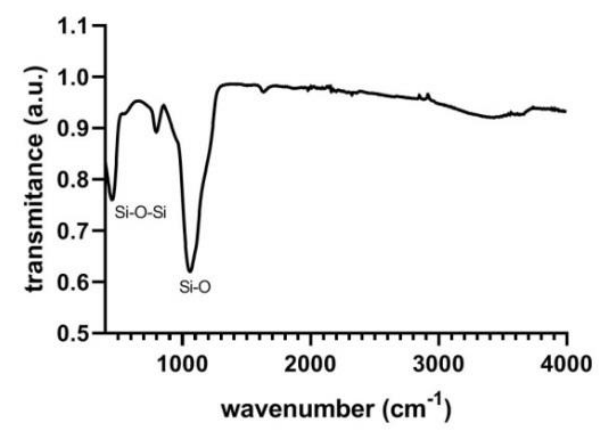

Figure 2: SH samples FT IR spectrum. a) SH-A; b) SH-B; c) SH-C; d) SH-D.

\subsection{Methods}

\subsubsection{Direct evaluation of the pozzolanic activity of cement pastes by modified Chapelle test.}

The modified Chapelle test was adopted to determine the amount or capacity of a mineral addition, by pozzolanic action, in fixing lime for formation of hydration compounds (ABNT NBR 15.895:2010 [21])

Once, the aim of this study was to compare the pozzolanic activity of SH with different particle size distributions and, therefore, different addition percentages to keep the resulting surface area equal for all samples, the Chapelle method dosage was modified. The content was based on the solid mass of $\mathrm{SiO}_{2}$ of each sample. The water mass present in SH was discounted to obtain an equal volume for all samples. Dosage specifications are presented in Table 3. 
Table 3: Dosage for Modified Chapelle Assay.

\begin{tabular}{c|c|c|c|c|c}
\hline \multirow{2}{*}{ SAMPLES } & $\begin{array}{c}\text { SUPERFICIAL } \\
\text { AREA }\end{array}$ & $\begin{array}{c}\text { SIO }_{2} \text { MASS FOR } \\
\text { CHAPELLE METHOD }\end{array}$ & $\begin{array}{c}\text { RESULTANT SUPER- } \\
\text { FICIAL ÁREA (SH) }\end{array}$ & $\begin{array}{c}\text { TOTAL MASS } \\
\text { OF SH }\end{array}$ & $\begin{array}{c}\text { WATER } \\
\text { MASS }\end{array}$ \\
\cline { 2 - 6 } & $\mathrm{m}^{2} / \mathrm{g}$ & $\mathrm{g}$ & $\mathrm{m}^{2} / \mathrm{g}$ & $\mathrm{g}$ & $\mathrm{g}$ \\
\hline SH-A & 80.00 & 1.00 & 80.00 & 2.00 & 249.00 \\
\hline SH-B & 270.00 & 0.29 & 80.00 & 0.74 & 249.55 \\
\hline SH-C & 310.00 & 0.26 & 80.00 & 0.86 & 249.39 \\
\hline SH-D & 750.00 & 0.11 & 80.00 & 0.71 & 249.39 \\
\hline
\end{tabular}

\subsubsection{Cement paste dosage for compressive strength and FT IR tests}

The cement paste dosages were based on ABNT NBR 7215:2019 [22], the same one used for the cement mortar compressive strength tests. The addition content added to the cement paste depended on the surface area of each sample as it was desired to match the final surface area of each SH. In addition, the content was based on the solid mass of $\mathrm{SiO}_{2}$ of each sample in relation to the cement mass. The water mass presented in $\mathrm{SH}$ was discounted to obtain an equal w/c ratio for all samples. Table 4 shows the proposed mass dosage of each material present in the cement paste. Since SH-A had a larger particle size and therefore a smaller surface area, it was added at a higher content (3\%) than the other samples. SH-B, SH-C and SH-D, due to their growing surface areas, were added at $0.89 \%, 0.77 \%$ and $0.32 \%$, respectively

Table 4: Dosage of cement pastes for mini-slump, mechamical strenght and FT IR tests for each SH sample.

\begin{tabular}{l|l|l|l|l|l}
\hline $\begin{array}{l}\text { CEMENT } \\
\text { PASTE }\end{array}$ & CEMENT & WATER & SIO $_{2}$ & SH & $\begin{array}{l}\text { RESULTANT } \\
\text { SUPERFICIAL ÁREA (SA) }\end{array}$ \\
\cline { 5 - 7 } & & & & & \\
\hline REF & $100.00 \%$ & $48.00 \%$ & - & - & - \\
\hline SH-A & $100.00 \%$ & $48.00 \%$ & $3.00 \%$ & $6.00 \%$ & 2400.00 \\
\hline SH-B & $100.00 \%$ & $48.00 \%$ & $0.89 \%$ & $2.20 \%$ & 2400.00 \\
\hline SH-C & $100.00 \%$ & $48.00 \%$ & $0.77 \%$ & $2.55 \%$ & 2400.00 \\
\hline SH-D & $100.00 \%$ & $48.00 \%$ & $0.32 \%$ & $2.10 \%$ & 2400.00 \\
\hline
\end{tabular}

\subsubsection{Cement mass flow evaluation by mini-slump test}

The mini-slump test was used to evaluate the possible influence of additions on fresh cement pastes. The mini-slump method was described by KANTRO [23] and consists of evaluate the spreading of the fresh cement past in a graduated glass or ceramic table. After spreading stops, with the aid of a ruler, two perpendicular diameters shall be measured, and the values averaged. The number of representatives represents the spread of the tested mass.

\subsubsection{Evaluation of $\mathrm{SH}$ influence in compressive strength of cement pastes by mechanical rupture}

The cylindrical specimens for compression rupture testing were moulded based on ABNT NBR 7215:2019 [22]. Each cement paste was prepared for rupture evaluation at ages of 1, 3 and 7 days. Nine specimens of dimensions of $(50.00 \times 100.00) \mathrm{mm}$ were dosed for each cement paste. From this set, 3 specimens were tested for each age of rupture, totalling 45 ones.

The mixture of the components was performed in a low speed industrial blender. The mixture of water with cement was performed for 90 seconds and then, with a spatula, the material retained in the blender wall was removed and the $\mathrm{SH}$ was added, less for the reference sample. After this procedure, the blender was activated again for more 60 seconds.

After dosing, the cement masses were kept for the first $24 \mathrm{~h}$ in a humid chamber with humidity above 95\%. After this period, as demoulded, the cement masses related to 3 and 7 were submerged in a lime water bath until the age of rupture. Cement masses related to 1 day were tested shortly after demolding. To perform the compression tests, a duly calibrated EMIC test machine model DL 10,000 was used. 


\subsubsection{Evaluation of $\mathrm{Ca}(\mathrm{OH})_{2}$ consumption by FT IR}

For the FT IR tests, cement pastes were prepared with the dosage specifications shown in Table 4. These were stocked in containers at $20{ }^{\circ} \mathrm{C}$ and stored under vacuum until the curing age of 7 days to avoid carbonation of the pastes. At the age of analysis, the cement pastes were ground to fine particle size and passed through a 200 mesh sieve. For ATR, the samples were placed under direct contact with the diamond crystal. All measurements were collected in the range of $4000-400 \mathrm{~cm}^{-1}$. Spectra were measured at $4.0 \mathrm{~cm}^{-1}$ resolution, accumulating a total of 32 scans per sample analysed. After the measurements, the spectra had their baseline corrected and were normalized for comparison. In order to explain the significant increase in compressive strength of the samples with SH addition, FT IR analyses were performed for samples with and without SH for 7 days of cure.

\section{RESULTS AND DISCUSSION}

\subsection{Evaluation of the pozzolanic activity of cement pastes through the modified Chapelle test.}

The data obtained by the modified Chapelle method assay are presented in Table 5.

Table 5: Modified Chapelle results for each SH sample.

\begin{tabular}{c|c|c|c}
\hline \multirow{2}{*}{$\begin{array}{c}\text { SAM- } \\
\text { PLES }\end{array}$} & $\begin{array}{c}\mathrm{HCl} \text { MÉDIUM VOLUME } \\
\text { USED FOR TITULATION }\end{array}$ & $\begin{array}{c}\text { HCI CORRECTION } \\
\text { FACTOR 0.1 M }\end{array}$ & $\begin{array}{c}\text { CHAPELLE } \\
\text { INDEX }\end{array}$ \\
\cline { 2 - 2 } & $\mathrm{mL}$ & & $\mathrm{Ca}(\mathrm{OH})_{2} \mathrm{mg} / \mathrm{g}$ \\
\hline REF & $54.4 \pm 0.10$ & \multirow{3}{*}{1.04} & - \\
\hline SH-A & $20.30 \pm 0.10$ & & 1037.00 \\
\hline SH-B & $47.60 \pm 0.10$ & & 880.00 \\
\hline SH-C & $45.30 \pm 0.10$ & & 1352.00 \\
\hline SH-D & $46.00 \pm 0.10$ & & 3018.00 \\
\hline
\end{tabular}

The sample of $\mathrm{SH}-\mathrm{A}$ had the lowest $\mathrm{HCl}$ expenditure for titration, demonstrating higher $\mathrm{Ca}(\mathrm{OH})_{2}$ consumption among all samples. The $\mathrm{HCl}$ volume expenditure compared to the reference was $62.68 \%$ lower for the CS-A sample.

The remaining samples, SH-B, SH-C and SH-D showed similar $\mathrm{HCl}$ volume expenditure results, of which sample SH-B presented the lowest consumption values. The value obtained was approximately $12.50 \%$ lower than that resulting from the reference test. In addition, the titration $\mathrm{HCl}$ consumption of the SH-A sample was $57.35 \%$ lower than SH-B sample.

Thus, the results obtained for $\mathrm{HCl}$ volume expenditure indicate that for the same surface addition area the sample SH-A, which has the largest particle size and percentage of addition, achieved the higher consumption of $\mathrm{Ca}(\mathrm{OH})_{2}$. The results showed that the efficiency of the pozzolanic reaction in a system containing $\mathrm{CS}$ and $\mathrm{Ca}(\mathrm{OH})_{2}$ was not only dependent on the surface area of the nanoparticles but also on their size and their addition content.

However, when the results are analysed considering that $\mathrm{SH}$ addition levels would be equal for all samples, therefore $1.00 \mathrm{~g}$ of material of each $\mathrm{SH}$, the sample SH-D presented better pozzolanic performance. As is shown in Table 5, analysing the results in terms of modified Chapelle Index, expressed as consumption of $\mathrm{Ca}(\mathrm{OH})_{2} \mathrm{mg}$ per $\mathrm{g}$ of material, it was possible to identify that the addition of $1.00 \mathrm{~g}$ of SH-D allowed a consumption of $3018.00 \mathrm{mg}$ of $\mathrm{Ca}(\mathrm{OH})_{2}$, while the addition of $1.00 \mathrm{~g}$ of SH-A reacts with only $1037.00 \mathrm{mg}$.

The sample SH-A presented lower consumption of $\mathrm{HCl}$ and therefore higher amount of $\mathrm{Ca}(\mathrm{OH})_{2}$ reacted because it was added in a larger amount than the other samples, for the equality of surface areas among all. But when analysing the results, considering equal addition contents and different surface areas, the SH-D silica nanoparticles showed better pozzolanic performance. It corroborated with the results obtained by the authors [11-14], that indicated that the smaller the individualized nanoparticle size and therefore the larger surface area, the higher the pozzolanic activity index will be. Except for this trend, the sample $\mathrm{SH}-\mathrm{B}$ showed lower $\mathrm{Ca}(\mathrm{OH})_{2}$ consumption than $\mathrm{SH}-\mathrm{A}$, which has a larger particle size. 


\subsection{Evaluation of the flowability of cement pastes by means of the mini-abatement test}

Scattering data as well as temperature and humidity are presented in Table 6 . There was a decrease in the average scattering diameter for samples with $\mathrm{SH}$ addition and this was verified for those with higher content of addition. It is possible to observe that the cement paste with SH-A addition (CP SH-A), presented smaller scattering while the reference obtained greater fluidity among all the samples.

Table 6: Mini-slump tests results for each SH sample.

\begin{tabular}{c|c}
\hline \multirow{2}{*}{ SAMPLES } & MEDIUM DIAMETER OF SCATTERING \\
\cline { 2 - 2 } & $\mathbf{m m}$ \\
\hline REF & $45.00 \pm 10.00$ \\
\hline CP SH-A & $35.00 \pm 10.00$ \\
\hline CP SH-B & $38.00 \pm 10.00$ \\
\hline CP SH-C & $38.00 \pm 10.00$ \\
\hline CP SH-D & $40.00 \pm 10.00$ \\
\hline
\end{tabular}

Based on the measurement error it was possible to verify that the spreading results obtained by the cement pastes CP SH-D, CP SH-C and CP SH-B were statistically equal. The observed loss of workability agrees with the literature $[9,15]$. However, this loss of scattering, did not affect the confection of the specimens, which were molded and did not disaggregate after the unmold. As is shown in table 6 the workability loss of cement pastes increased with increasing $\mathrm{SH}$ addition content, that is higher for CP SH-A and lower for CP SH-D.

\subsection{Evaluation of SH influence in compressive strength of cement pastes by mechanical rupture}

As is shown in Figure 3, for all samples with addition of SH, it was possible to identify an increase in the mechanical compressive strength with the advancing age of analysis and in relation to the reference sample. This was significantly higher for the cement paste CP SH-A, with addition of SH-A at a concentration of 3\% by mass per cement mass. The paste presented the highest strength value for all ages analysed. In addition, it was obtained an increase of resistance in relation to the reference sample, from $46.32 \%, 20.00 \%$ and $24.25 \%$ for 1.3 and 7 days, respectively.

In addition, it can be noted that pastes with $3 \% \mathrm{SH}-\mathrm{A}$ and $0.7 \% \mathrm{SH}-\mathrm{C}$ addition allow the cementitious compound to achieve a mechanical strength in 3 days of cure, higher than the reference sample in 7 days. That is, with the addition of the product, a resistance of 7 days was reached with only 3 days of cure. In practical terms, for example, this could reduce construction lead times and increase production efficiency for precast.

The results also showed that the reference cement paste presented the lowest compressive strength values for all ages. This indicates that the addition of $\mathrm{SH}$, even at low concentrations, was capable of increasing the mechanical strength of cementitious composites.

Another important information that was identified in the results is that the increase in compressive strength obtained from 1 day to 3 days of cure was greater for the reference sample. While the reference cement paste obtained a $101 \%$ increase from 1 day to 3 days of cure, the increase for samples CP SH-D, CP SH-C, CP SH-B and CP SH-A was 72.83\%, 71.18\%, 67.50 and $65.33 \%$, respectively. This possibly indicates that the action of $\mathrm{SH}$ was more intense in the first 24 hours of hydration, acting as a C-S-H nucleation site and consuming $\mathrm{Ca}(\mathrm{OH})_{2}$ as it was formed [3, 9, 14]. After 1 day of hydration, the action of nanosilica tended to decelerate and the difference in resistance between the added samples and the reference sample tends to decrease.

Based on ANOVA and Tukey test demonstrated in Figure 4, it was possible to verify that the mechanical strength results obtained by the cement pastes CP SH-D, CP SH-C and CP SH-B were statistically equal for all ages. The sample with the addition of $\mathrm{SH}-\mathrm{C}$ presented slightly higher results than the others, but it was not statistically significant increase.

The mechanical strength values found show that for the same total surface area of $\mathrm{SH}$ added, the cement paste with the addition of 3\% SH-A, with the largest particle size, presented better performance than the others. This indicated that for the effect of mechanical resistance it was not only the surface area of SH that influences, but also the size and concentration of the addition. 
However, by analysing the result em terms of relative influence, that is, strength increased compared to \% SH mass addition the sample of CP SH-D showed better performance. This is because, with the addition of only $0.32 \%$ by mass per cement mass, the paste presented resistance increase of $19 \%, 2 \%$ and $8 \%$, for the rupture ages of 1, 3 and 7 days respectively. While, the addition of 3.00\% of SH-D increased the compressive strength by $46.32 \%, 20.00 \%$ and $24.25 \%$ for 1,3 and 7 days, respectively.

Therefore, according to the obtained results in the compression test, it was possible to identify that the smaller the size and larger surface area of the individualized particle, the better its performance to increase strength of cement paste, when added in equal amounts. This data was consistent with the conclusions obtained in the literature [6-8, 11-14].

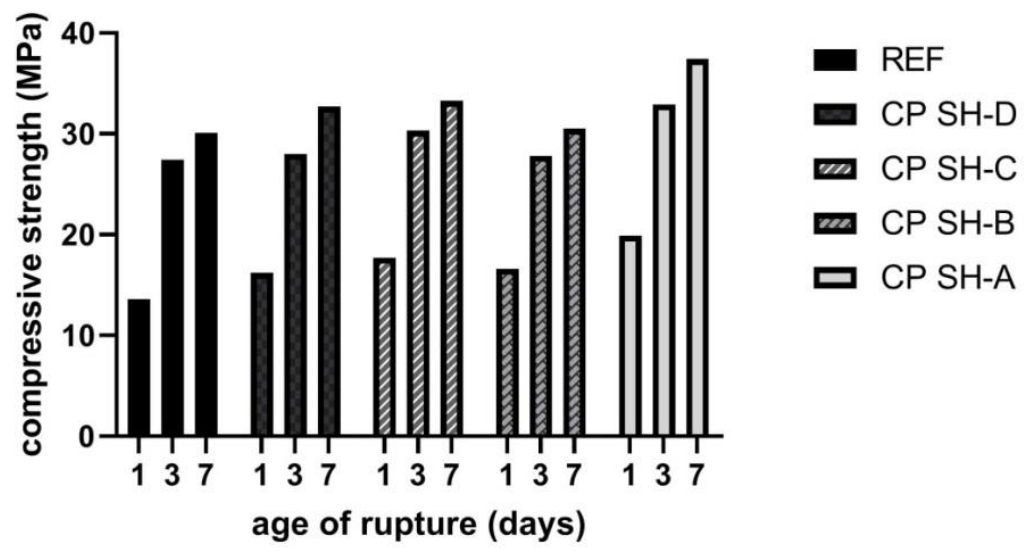

Figure 3: Medium compressive strength for 1,3 and 7 days of rupture.

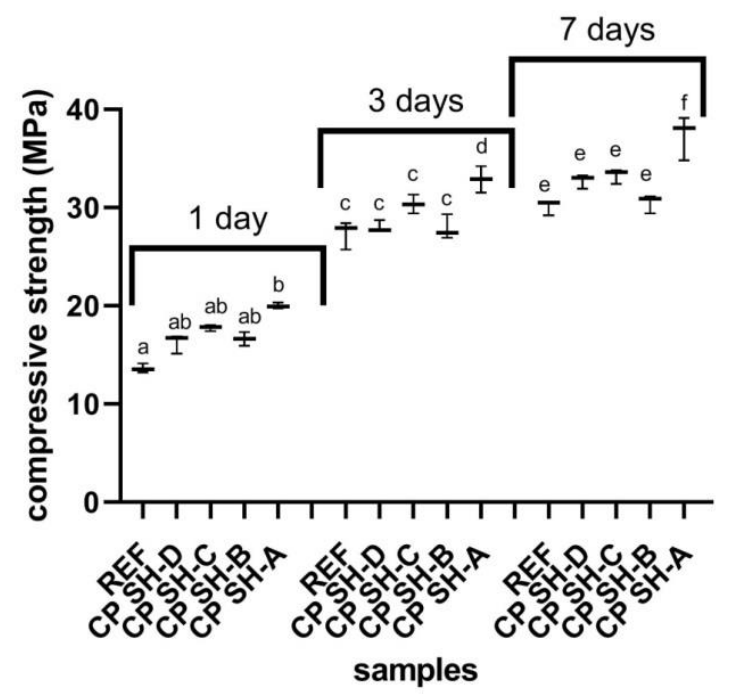

Figure 4: Compressive strength for 1,3 and 7 days of rupture. Equal letters represent values that do not show significant differences between them, while different letters represent significant differences according to the ANOVA and tukey test.

\subsection{Evaluation of $\mathrm{Ca}(\mathrm{OH})_{2}$ consumption by FT IR}

Based on literature [19] and according to Figure 5, it was possible to observe that there is a band at $3640 \mathrm{~cm}^{-1}$ wavelengths, which is related to the stretching movement of crystallized hydroxyl $\left(\mathrm{OH}^{-}\right)$groups in the calcium hydroxide structure. For 7 days of hydration, it was possible to identify that there is a lower presence of $\mathrm{Ca}(\mathrm{OH})_{2}$ in the sample $\mathrm{SH}-\mathrm{A}$, indicating higher consumption of this structure by the addition of $\mathrm{SH}$. Next, the sample with the second smallest $\mathrm{Ca}(\mathrm{OH})_{2}$ peak area is $\mathrm{SH}-\mathrm{C}$ and finally having the largest peak area, we have the reference sample. This indicated that amorphous silica consumed calcium hydroxide, forming C-S- 
$\mathrm{H}$ gel, thereby aiding in gaining mechanical strength.

The data found for the curing age of 7 days by the FT IR equipment indicate that the addition that presented the best performance in relation to consumption of $\mathrm{Ca}(\mathrm{OH})_{2}$ was the SH-A sample. This is in agreement with the information obtained in the compressive strength and modified Chapelle tests.

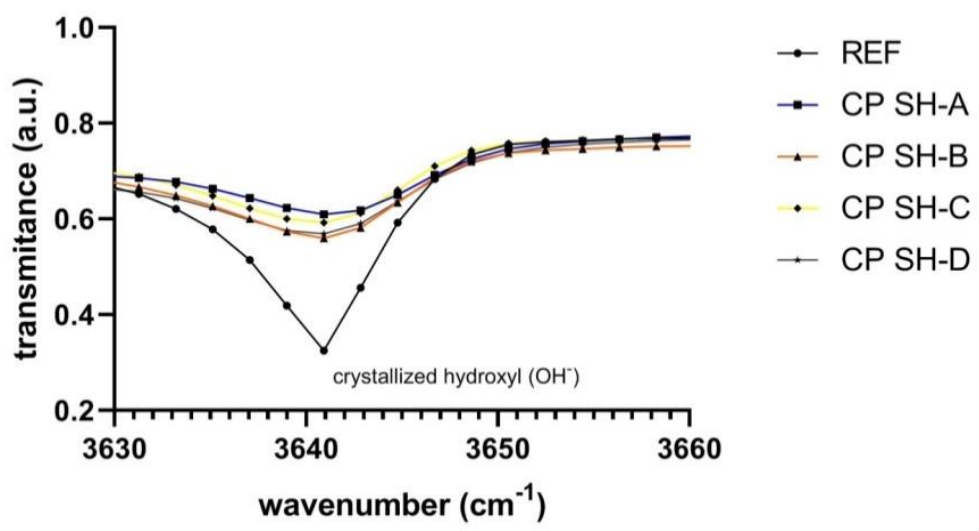

Figure 5: FT IR spectroscopy for cement paste samples after 7 days of aging.

\section{CONCLUSIONS}

When the surface areas are equalized, according to the SH addition levels, it was observed that the sample that promoted the best mechanical strength in the cement paste and that presented the highest $\mathrm{Ca}(\mathrm{OH})_{2}$ consumption was the SH-A. The data obtained are convergent, indicating that particle size and especially the addition percentage of SH have influence on total performance of SH nanoparticles reaction with $\mathrm{Ca}(\mathrm{OH})_{2}$.

By equalizing the resulting surface areas, the addition concentration becomes the predominant variable for reaction efficiency evaluation. This possibly occurs because a lower concentration of addition, decreases the probability of SH to react with the total $\mathrm{Ca}(\mathrm{OH})_{2}$ of the medium and therefore, lower efficiency was verified. In addition, smaller nanoparticles have higher surface reactivity and therefore become easier to agglomerate, and consequently this may also reduce their efficiency in the pozzolanic reaction, compared to other samples that have been added in larger quantities

The results obtained are important for a better understanding of the variables that control the efficiency of SH addition in cement pastes and possibly in cementitious composites. The greater knowledge about the nano additions that can be used in construction aims to increase the material yield and promote cost reduction in the sector.

\section{ACKNOWLEDGMENTS}

The authors thank the LACTEC Institute; LACTEC/IE and the Next Chemical company for their support in the laboratory analyses.

\section{BIBLIOGRAPHY}

[1] GARCIA, D.C.S., SOARES, M.M.N.S., BEZERRA, A.C.S, et al., "Microstructure and hardness of cement pastes with mineral admixture", Revista Matéria, v.22, n.2, Set. 2017.

[2] SENFF, L., HOTZA, D., REPETTE, W.L. "Rhelogycal behaviour of cement pastes with addition of silica fume, nanosilica and polycarboxilic dispersant", Revista Matéria, v.15, n.1, pp.12-20, Fev.2010.

[3] HOU, P., QIAN, J., CHENG, X., et al., "Effects of the pozzolanic reactivity of nanoSiO ${ }_{2}$ on cementbased materials", Cement and Concrete Composites, v. 55, pp. 250-258, Jan. 2015.

[4] KONG, D., CORR, D.J., HOU, P., et al., "Influence of colloidal silica sol on fresh properties of cement paste as compared to nano-silica powder with agglomerates in micron-scale". Cement and Concrete Composites, v. 63, pp.30-41, Oct. 2015.

[5] ABREU, G. B., COSTA, S.M.M., GUMIERI, A. G., et al., "Mechanical properties and microstructure of high-performance concrete containing stabilized nano-silica", Revista Matéria, v.22, n.2,2017.

[6] FLORES, Y.C., CORDEIRO,G.C., TOLEDO FILHO,R.D., et al., "Performance of Portland cement pastes containing nano-silica and different types of sílica", Construction and Building Materials, v.146, pp. 
524-530, Aug. 2017.

[7] OLTULU, M., SAHIN, R., "Effect of nano-SiO2, nano-A12O3 and nano-Fe2O3 powders on compressive strengths and capillary water absorption of cement mortar containing fly ash: A comparative study", Energy and Buildings, v. 58, pp. 292-301, Mar. 2013.

[8] KUNTHER, W., FERREIRO, S., SKIBSTED, J., "Influence of the Ca/Si Ratio on the Compressive Strength of Cementitious Calcium-Silicate-Hydrate Binders", Journal of Materials Chemistry A, v. 5, n.33, pp. 17401-17412, Jul. 2017.

[9] QING, Y., Zenan, Z., Deyu, K., et al., "Influence of nano-SiO2 addition on properties of hardened cement paste as compared with silica fume", Construction and Building Materials, v.21, pp. 539-545,Mar. 2007.

[10] SINGH, L. P., BHATTACHARYYA, S. K., SINGH, P., et al., "Granulometric synthesis and characterisation of dispersed nanosilica powder and its application in cementitious system", Advances in Applied Ceramics, v. 111, pp. 220-227, Nov.2013.

[11] GAITERO, J. J., CAMPILLO, I., GUERRERO, A., "Reduction of the calcium leaching rate of cement paste by addition of silica nanoparticles", Cement and Concrete Research, v. 38, pp. 1112--1118, Aug. 2008.

[12] BERRA, M., CARASSITI, F., MANGIALARDI, T., et al., "Effects of nanosilica addition on workability and compressive strength of Portland cement pastes", Construction and Building Materials, v. 35, pp. 666-675, Oct. 2012.

[13] RUPASINGHE, M., SAN NICOLAS, R., MENDIS, P., et al., "Investigation of strength and hydration characteristics in nano-silica incorporated cement paste", Cement and Concrete Composites, v. 80, pp. 1730, Jul. 2017.

[14] ZHANG, X., YANG, H., YANG, Q., et al., "Effects of particle size of colloidal nanosilica on hydration of Portland cement at early age", Advances in Mechanical Engineering, v.11, n.2, pp. 1-9, Feb. 2019.

[15] DURGUN, M.Y., ATAHAN, H.N., "Strength, elastic and microstructural properties of SCCs' with coloidal nano sílica addition". Construction and Building Materials. v.1258, pp.295-307, Jan.2018.

[16] ASSOCIAÇÃO BRASILEIRA DE NORMAS TÉCNICAS. Cimento Portland - Requisitos. NBR 16697:2018. Rio de Janeiro, 2018.

[17] ASSOCIAÇÃO BRASILEIRA DE NORMAS TÉCNICAS. Água para amassamento do concreto. Parte 1: Requisitos. NBR 15900-1:2009. Rio de Janeiro, 2009.

[18] HOPPE FILHO, J., GOBBI, A., PEREIRA, E., et al., "Pozzolanic activity of mineral additions to Portland cement (Part I): Pozzolanic activity index with lime (PAI), X-ray diffraction (XRD), thermogravimetry (TG/DTG) and modified Chapelle", Revista Matéria, v.22, n.3, Jun. 2017.

[19] OU, Z., MA,B., JIAN, S.," Comparison of FT-IR, Thermal Analysis and XRD for Determination of Products of Cement Hydration", Advanced Materials Research, v.168-170, pp. 518-522, Dec.2010.

[20] METIN, C.O., LAKE, L.W., MIRANDA, C.R., et al., "Stability of aqueous silica nanoparticle dispersions", Journal of Nanoparticle Research, v.13, n.2, pp.839-850, Set. 2010.

[21] ASSOCIAÇÃO BRASILEIRA DE NORMAS TÉCNICAS. Materiais pozolânicos - Determinação do teor de hidróxido de cálcio fixado - Método Chapelle modificado. NBR 15.895:2010. Rio de Janeiro, 2010.

[22] ASSOCIAÇÃO BRASILEIRA DE NORMAS TÉCNICAS. Cimento Portland - Determinação da resistência à compressão de corpos de prova cilíndricos. NBR 7215:2019. Rio de Janeiro, 2019.

[23] KANTRO, D. L. "Influence of water-reducing admixtures on properties of cement paste: a miniature slump test", Cement, Concrete and Aggregates, v. 2, n. 2, pp. 95-102, 1980

\section{ORCID}

Diogo Augusto da Silva de Assis https://orcid.org/0000-0003-4640-4329

Mariana d'Orey Gaivão Portella Bragança ～https://orcid.org/0000-0002-2702-7196 